\title{
Emotion Focussed Cognitive Behavioral Therapy: An Attempt to Resolve Emotional Deficiency and Strengthen Cognitive Behavioral Therapy Efficacy
}

\author{
Arbin Janu Setiyowati \\ State University of Malang, Indonesia \\ arbin.janu.fip@um.ac.id
}

\begin{abstract}
Cognitive behavioral therapy (CBT) is counseling approach which its efficacy is widely recognized. CBT is the only approach that is highly scalable and systematically, emphasizing the symptom of problematic behavior, hence behavior changes after therapy can be observed and measured. However, behind its efficacy, CBT is not yet able to accommodate all the needs of the counselee. Counselee needs less attention is the emotional aspects of the counselee. This is due to CBT concerns is on the behavioral symptoms rather than on how to comprehend counselees problem. It limits CBT ability to facilitate counselee holistically. To overcome the aforementioned conditions, emotion focused cognitive behavioral therapy (ECBT) offers the effort to help the counselee by combining CBT and emotional engagement in the process of assisting the counselee. ECBT use all empirically-based component of traditional CBT and include components to overcome the additional deficit of the emotion on the problems faced by each counselee. ECBT is considered effective because, in the process of counseling, counselee is invited to recognize and manage emotions within him or herself related to problems occurring. Comprehensive ECBT system is considered able to reinforce the efficacy of CBT in helping counselees problems.
\end{abstract}

Keywords: ECBT, emotional deficit, CBT

\section{INTRODUCTION}

A number studies have demonstrated the effectiveness of cognitive behavioral therapy (CBT) in addressing various individual issues ranging from education to the health aspects. It is widely believed that CBT is able to perfectly cope in dealing counselees with varying degrees of problems ranging from agile to severe issues. Counselees addressed using CBT therapy showed satisfactory behavior change. Counselees changes in behavior can be measured through behavior comparison between before and after therapy.

Prodigious CBT performance makes CBT is very popular and serves as an option to help troubled individuals. There are almost no mistakes found in any CBT intervention. Despite its prodigious performance, some criticism aimed at CBT occur. CBT intervention which focuses on the efforts of counselees' thought discovery to identify the root problem and contribution to the emergence of maladaptive behavior disregards the human as a whole individual, which consists of cognitive, affective (in this case the emotion) and psychomotor. The problems faced by counselees are considered finished when counselees experience behavior changes. Actually, the behavior is changing from maladaptive to more adaptive behavior, yet CBT ignores counselee in terms of emotion.

Emotion activates a sense in each behavior performed by the individual. Emotion creates an individual's life becomes more vibrant. Both positive and negative emotion within individual creates a vibrant life. During the therapy carried out by a certain individual which accentuates on the actual symptom, it is believed that the therapy is succeeded in altering individual's behavior. However, the individual remains feeling empty which is unfulfilled during therapy. In addition, it encourages the individual to perform rigid behavior without an involvement of emotion.

Counselee who experience problems has no idea to manage their emotional experience. Therefore, the individual experience an excessive anger and fear or possesses insufficient emotional control in keeping up with the problem they encountered (Power, 2010). The aforementioned circumstance is considered delicate if it is continuously ignored since the ability of the individual in recognizing and managing emotion serve as paramount ability during self and social adaptation of the individual concerned.

Emotion ignored within CBT therapy creates insignificant changing on the individual concerned. The individual, subsequently, will feel abandoned and marginalized which individual problems will have no ending without the involvement of their feeling. This condition, particularly for counselee treated using CBT, will feel empty in terms of feeling. Therapy sessions performed by the individual will not accommodate individual necessity as a complete human being.

The feeling of emptiness felt by the counselee treated using CBT is believed as incomplete problem resolving. Counselees' problem is considered resolved the moment the entire elements within counselee is sufficiently accommodated such as past experiences of counselee which developed scars or traumatic condition as a source of the current negative behavior of counselee. Emotional elements identification of counselee is imperative to be performed by the therapist. It is necessary since therapist ought to understand counselee's limitations and durability in performing CBT therapy, particularly on selfconfidence encouragement and thinking construction which influences maladaptive behavior.

The attempt to encourage self-confidence or construct counselee's thinking as an initial approach in CBT will not effectively be performed, or in the worst case, it will fail if the therapist could not comprehend counselee's emotion. If the therapist could comprehend counselee's emotion, counselee's will then consider the therapist is immensely taking care of them and will assist the counselee to resolve the problems. When counselee's self-confidence is activated, counselee will completely involve him or herself in the process of therapy. Complete involvement and commitment of counselee are paramount within CBT therapy since it 
deals with its efficacy. Pursuant to the abovementioned problem, it is important to scrutinize as well as criticizing CBT to provide an improvement on CBT efficacy in assisting diverse and complex issues within the individual. As a part of CBT development, Emotion Focused Cognitive Behavioral Therapy or abbreviated as ECBT is suggested to conclude CBT's minus points.

\section{COGNITIVE BEHAVIORAL THERAPY (CBT) AND ITS EFFICACY}

Cognitive Behavioral Therapy (CBT) is defined as a psychological approach which is in accordance with scientific principle. Its efficacy in assisting individual has been proven through several types of research performed. After a therapeutic alliance is established, counselee and therapist cooperate to identify and comprehend issues in correlation with thinking, feeling, and behavior.

This approach deals with current condition and feeling and relies upon the attempt of therapist and counselee in developing aligned perspective regarding issues encountered. Inherently empowered treatment aims at assisting counselee to resolve their problems by utilizing ability possessed by the counselee (Corey, 2011). The acquisition and utilization of such skills are seen as a primary goal and an active component in promoting change with an emphasis on putting what has been learned in practice between sessions (PR). Thus, the overall goal for the individual is to repair their problems by their own efforts, in cooperation with psychotherapy.

The therapeutic relationship is seen as an important element, however, unlike other psychotherapy that is not seen unpacking the main vehicle of change, it focuses on collaborative work on issues that have been agreed (Capuzzi \& Douglas, 2007). This is a way to help counselee which is aligned with the basis of equal partnership, each party contributes to the therapeutic relationship. The therapist contributes the skills and knowledge of the psychological process, emotional theory, and techniques required to help the counselee. While counselee is considered as individual capable of comprehending his or her own experience alongside with ability he or she possesses.

Problematic counselee often experiences irrational thinking which strengthens his or her perception. That perception, then, generates a maladaptive behavior which at the end of the day ruin the entire aspects of his or her life. As a result of a negative pattern of thinking, the individual might avoid the social situation or ignore a chance to develop him or herself in working places or school.

To nullify and neutralize negative pattern of thinking and destructive behavior, CBT therapy assists the counselee in identifying a problem within his or her perceptions. This stage, commonly known as functional analysis, is important for the counselee to understand how thinking, feeling, and situation could contribute to maladaptive behavior. This process could take longer time and become the most difficult time for them. However, at the end of the day, it could manufacture a self-discoveries, self-understanding, and knowledge which take a role as an important element within therapy process.

The second part of CBT focuses on actual behavior which contributes to the problems. Counselee starts to learn new thing and skill to be utilized in the real world. For instance, individual addicted to the drug might habituate her or himself to learn new thing and accustom to avoid or handle the social situation which encourages the individual to do the maladaptive behavior. In this case, the role of homework is paramount. Altered behavior will be easily developed in the actual situation if the counselee is willing to train new skill frequently in each session (Ivey et al., 2009).

In most cases, CBT is a gradual process that helps an individual to take steps towards additional behavior changing (Dobson, 2010). Counselees who suffer from social anxiety might start with just imagine himself in social situations which cause anxiety. Furthermore, the counselee might begin to practice conversations with friends, family, and acquaintances. By performing a significant attempt to the greater goal, the practice becomes easier in order to achieve the objectives.

Recently, CBT therapy is an approach which is commonly employed in psychotherapy to assist mental disorder and empirically proven effective (Leichsenring et al., 2006). Recovery attempt which is based on the basis of solid evidence derived from controlled studies employing random and methodology of a case that has demonstrated efficacy and effectiveness of CBT in general mental disorder recoveries, including anxiety, general anxiety, hysteria, phobia, obsessive-compulsive disorder, post-traumatic stress disorder, bulimia, and depression. CBT model has also developed for a number of attempts to assist heavy mental disorders by combining with Pharmacotherapy such as psychosis, schizophrenia, bipolar disorder, anger and pain management, physical health adaptation, insomnia, and organic syndrome, for instance, the initial stage of dementia (Wiles et al., 2014).

There is a wide research basis within a behavioral approach in working with counselees children and people with learning disabilities, severe mental health problems and generally challenging behavior. Recently CBT has become the treatment of choice for depression in adolescents, and children with the intellectual problem. A study of CBT shows the contribution to psychological factors for physical health issues. The use of CBT by social workers in their practices is increasing, because CBT is in accordance with the values of social workers especially in the aspect of social justice (Prendez, 2012). The development of computer-based CBT, web, and phone effectively manage the problem of general mental disorders (McCrone et al. , 2004; Cavanagh et al. 2006; Ehde et al. , 2014)

In order to obtain the benefit from cognitive behavioral therapy (CBT), it requires a complete commitment and involvement of the counselee. In addition, since it is structured, CBT is less suitable for individual who possesses more complex mental disorders, or students who have learning difficulties. 
This is reinforced by Taylor's (2014) findings which reveal that $\mathrm{CBT}$ is effective in preventing depression among students but can not work well to tackle diverse school problems. Some critics also argue that because the CBT therapy only deals with the ongoing problems and focuses on issues that are very specific. CBT is considered not address the cause of the possibility of health conditions mental, such as a troubled childhood.

\section{EMOTION FOCUSED COGNITIVE THERAPY (ECBT) AND ITS EFFICACY}

Most CBT therapy program focus on modifying cognitive (maladaptive thinking pattern) and behavior (for instance, avoiding) to resolve the problems within counselee. CBT assists counselee to comprehend cognition aspect which contributes to the occurrence of maladaptive behavior and to develop a plan in handling the situation which causes problems. Counselee, then, implement what he or she learns in the real world. The study conducted concerning on the implementation of CBT therapy generally demonstrate that CBT could facilitate and accommodate wide emotion identification ability.

However, it is not sufficient to facilitate counselee in identifying and managing emotional experience apart from the current situation which he or she experiences. One reason possible concerning on the result of the study is counselee which experience a problem does not understand how to manage their emotional experience. Thus, the counselee experiences excessive anger and worry or even experience an emotional apparent in keeping up with a situation which causes a problem for the counselee.

Individual experiencing problems often illustrates a higher intensity and frequency in responding to the negative emotion. This individual possesses less ability in evaluating the negative emotional situation and more relies upon emotional channeling, where the risk of functional disorder and intense negative emotion increase. This condition creates the counselee less able to manage the emotional situation, for instance, counselee will express a less adaptive in managing the experience of anger, sadness, and worry compare to normal individual. At the end of the day, the problematic individual is expected to receive a more assistance rather than $\mathrm{CBT}$.

Emotion Focused Cognitive Behavioral Therapy (ECBT) employs the entire empirical component of conventional CBT and include additional components to resolve emotional deficiency related to issues which are experienced by each counselee. The basic difference between CBT and ECBT is the systematic integration of emotional concept related to ECBT. ECBT facilitates emotional development, both emotional understanding, and emotional regulation ability. Both treatments are compromised within two parts.

During the first stage of ECBT, counselee learns to discover different emotions (worry, anger, guilt, joy, and etc), and focus on emotional confession within counselee and another individual. In the second half of therapy, intervention is focused on counselee exploration using current emotion exploration on the situation which ignites other emotion (for instance anger) where counselee experience a difficulty in managing it. Counselee, then, is asked to manage those emotional experience, and at the end, counselee is given the opportunity to learn to practice in the actual situation. Therefore, counselee will possess the ability to manage diverse kinds of emotion.

Several studies demonstrate that the implementation of ECBT is effective, particularly to resolve worry issue within children. Suveg et al., (2006) showed that the ECBT is effective to help teenagers in coping with an anxiety issue. In the final session of the intervention, it showed the improvement in anxiety symptoms, emotional comprehension, emotional regulatory skills and increased overall function of the emotion itself. This increase in emotional skill is significant because emotional competence is an important component of adaptive psychological and social adjustment. The findings of this study provide strong initial support for the existence of ECBT.

Research conducted Afshari et al., (2014) reinforce the existence ECBT in helping counselees problematic especially anxiety issues. The result demonstrates that ECBT is effective to improve the coping abilities of anger, lower negative cognitive strategy, and the inability to manage anger in children. In addition, the findings of the study show that ECBT is able to reduce the inability to manage sadness and improve the ability of sadness coping.

The above research findings that demonstrate the efficacy of ECBT, show that the importance of emotions as an important component that influences behavior raised by individuals. ECBT is seen to have more benefits rather than CBT in addressing the problem of the counselee. ECBT emphasizing on understanding and managing emotions turned out to be very helpful for the counselees in understanding his or her emotion and is able to empower its emotional strength in the real environment that is realized in the form of adaptive behavior.

Diverse and complex problems experienced by counselee is indeed required a holistic treatment and approach. Human being perception as holistic elements ought to be understood by the therapist. When counselee encounters problems within him or herself and requires a psychological assistance, then the role of the therapist is to comprehend the problems encountered by counselee holistically. ECBT aims at taking into account that cognitive, emotion, and behavior are inseparable components. When therapist only focuses the treatment on one component, then the accomplishment of treatment upon counselee problem is questioned.

Problem accomplishment of counselee could not be seen only from the decreasing of symptom, problematic behavior, or from how counselee's thinking is being reconstructed (reconstructing irrational thinking which leads to problematic behavior). Yet, emotional aspect of counselee is also important to be taken into account. Emotional competence serves as a paramount component from psychological and social adaptation. 
Meaning that emotion and cognition are closely related (Power, 2010). The relation between emotion and cognition will be manifested through both adaptive and maladaptive behavior. Within ECBT therapy session, the role of the therapist is to generate and activate a new emotional experience corrected for the counselee. In addition, it is also beneficial for the counselee in order to be able to learn new thing and encourage an adaptive behavior in the actual situation. Hence, it is proven that in order to generate a corrective emotional experience within counselee, it is important to assist he or she in manufacturing his or her own emotion, accepting the emotion, and comprehending new meaning on such emotion.

Furthermore, by adding active technique which directs counselee to go through the certain emotional process will significantly increase the result at the end of therapy and in the advanced treatment (Thoma and McKay, 2015). To realize such a good result, it is important for a therapist in maintaining a strong relationship with the counselee, even within the structured and extensive procedure. In the end, the choice to use CBT or ECBT, even other approaches, will all be turned to the therapist's decision. How the therapist will use a particular approach in his or her work system to assist the counselee will depend on how the therapist looks at the substance of the counselee's problems. There is no perfect approach, but wise in choosing an approach tailored to the needs of the counselee is a preferable option.

\section{CONCLUDING REMARKS}

It can be concluded that behind its efficacy, counseling approach still has weaknesses. The weakness of a counseling approach is not seen as an obstacle in the assistance process but should be viewed as an opportunity to discover the other side of the approach for more exploration. This occurs in the CBT approach. All parties recognize that CBT is the most effective approach to the results in psychotherapy practice.

However, there is a gap where the emotional aspects of the counselee is not a priority in the process of assisting the counselee. This condition eventually resulted that the counselees still feel there is an empty part of him or herself despite receiving good counseling services. For that reason, ECBT was designed to complete the part of CBT which is considered as a weak point.

ECBT use all empirically-based component of conventional CBT and incorporate additional components to overcome the deficit-emotions related to the problems faced by every counselee. By employing ECBT, counselees will learn to recognize and accept and manage the emotions that lead the problem. By recognizing and managing the emotions he felt, it can achieve the needs of the counselee intact such as cognitive, affective and psychomotor aspects.

\section{REFERENCES}

[1] Afshari, A., Neshat-Doost, H. T., Maracy, M. R., Ahmady, M. K., \& Amiri, S. 2014. The Effective
Comparison Between Emotion-Focused Cognitive Behavioral Group Therapy and Cognitive Behavioral Group Therapy in Children with Separation Anxiety Disorder. Journal of Research in Medical Science, 19(3): 221-227.

[2] Capuzzi, D. G., and Douglas, R. 2007. Counseling and Psychotherapy. New Jersey: Pearson Education Inc.

[3] Cavanagh, K., Shapiro, D. A., VanDen-Berg, S., Swain, S., Barkham, M., and Proudfoot, J. 2006. The Effectiveness of Computerized Cognitive Behavioural Therapy in Routine Care. British Journal of Clinical Psychology, 45, 499-514.

[4] Corey, G. 2011. Theory and Practice of Counseling and Psychotherapy. Belmont: Brooks/Cole.

[5] Dobson, S. K. 2010. The Handbook Cognitive Behavioral Therapy. New York: The Guilford Press

[6] Ehde, D. M., Dillword, T. M., \& Turner, J. A. 2014 Cognitive-Behavioral Therapy for Individuals With Chronic Pain. American Psychological Association, 69(2).

[7] Ivey, E. A., D'Andrea, M., \& Ivey, B. M. 2009. Theories of Counseling and Psychotherapy: A Multicultural Perspective. New York: Pearson Education Inc.

[8] Leichsenring, F., Hiller, W., Weissberg, M., \& Leibing, E. 2006. Cognitive-Behavioral Therapy and Psychodynamic Psychotherapy: Techniques, Efficacy, and Indication. American Journal of Psychotherapy, 60(3).

[9] McCrone, P., Knapp, M., Proudfoot, J., Ryden, C., Cavanagh, K., Shapiro, D.A., Ilson, S., Gray, J.A., Goldberg, D., Mann, A., Marks, I., Everitt, B., Tylee, A. 2004. Cost-Effectiveness of Computerised Cognitive-Behavioural Therapy for Anxiety and Depression in Primary Care: Randomised Controlled Trial. Journal of Mental Health Policy and Economics, $185,55-62$.

[10] Power, M. 2010. Emotion Focussed Cognitive Therapy. UK: Wiley-Blackwell

[11] Prendez, G. A.A., Brisebois, K. 2012. CognitiveBehavioral Therapy and Social Work Values: A Critical Analysis. Journal of Social Work Values and Ethics, 9(2), 21-33.

[12] Suveg, Cynthia., Kendall, C.P., Comer, S.J., \& Robin, J. 2006. Emotion-Focused Cognitive-Behavioral Therapy For Anxious Youth: A Multiple-Baseline Evaluation. Journal of Contemporary Psychotherapy, 36(2), 77-85.

[13] Taylor, A. J., Phillips, R., Cook, E., Georgiou, L., Stallard, P., \& Sayal, K. 2014. A Qualitative Process Evaluation of Classroom-Based Cognitive Behaviour Therapy to Reduce Adolescent Depression. International Journal of Environmental Research and Public Health, 11(6), 5951-5969.

[14] Thoma, C. N., and Mckay, D. 2015. Working With Emotion in Cognitive Behavioral Therapy. London: The Guilford Press.

[15] Wiles, N., Thomas, L., Abel, A., Barnes, M., Carroll, F., Ridgway, N., Sherlock, S., Turner, N., Button, K., Odondi, L., Metcalfe, C., Owen-Smith, A., Campbell, J., Garland, A., Hollinghurst, S., Jerrom, B., Kessler, D., Kuyken, W., Morrison, J., Turner, K., Williams, C., Peters, T., and Lewis, G. 2014. Clinical Effectiveness and Cost-Effectiveness of Cognitive Behavioural Therapy as an Adjunct to Pharmacotherapy for Treatment-Resistant Depression in Primary Care: The CoBalT Randomized Controlled Trial. Health Technology Assessment, 18(31), 1-167. 